\title{
MODERNIDAD SINCOPADA: MÚSICA, RITMO Y NACIÓN EN LA OBRA DE MÁRIO DE ANDRADE ${ }^{1}$
}

\author{
Fernando Pérez Villalón \\ Departamento de Arte / Departamento de Lengua y Literatura \\ Universidad Alberto Hurtado \\ fperez@uahurtado.c
}

\section{RESUMEN / ABSTRACT}

Este ensayo aborda la obra del poeta brasileño Mário de Andrade, enfocándose en su ambigua relación con la música popular masiva de su época, a partir de la constatación de que en general el modernismo literario brasileño y la música popular masiva urbana que se consolida en el curso de los años 20 no se encuentran sino a posteriori, y sin embargo deben leerse en contrapunto para comprender mejor ciertos aspectos de ambos. Se investiga en particular el modo en que la noción de síncopa articula las complejas relaciones entre el ritmo, lo nacional, lo popular y la alta cultura en la obra de Mário como una metáfora de algunas de las contradicciones de la modernidad brasileña.

PALABRAS Clave: Mário de Andrade, modernismo brasileño, síncopa, música popular brasileña.

This essay studies the work of Modernist poet Mário de Andrade from the perspective of its ambivalent relation with the popular music of its time. This essay proposes that, despite the fact that Brazilian Literary Modernism and the urban popular music that emerged at the same time converge only later on, they must be studied in conjunction if they are to be fully understood. This essay focuses on the way in which the notion of "syncopation" articulates complex relations between rhythm, nationality, popular and high culture in Andrade's work, which can be read as metaphors of contradictions at the core of Brazilian modernity.

KEY WORDS: Mário de Andrade, Brazilian Modernism, syncopation, Brazilian popular music.

1 El presente ensayo fue elaborado en el contexto del proyecto Fondecyt $\mathrm{n}^{\mathrm{o}} 11100266$, “El ojo y la oreja: sobre algunos motivos en la poesía y poética brasileña del siglo XX”, del que el autor es investigador responsable. 
El presente ensayo aborda la obra de Mário de Andrade enfocándose en la ambigua relación del escritor con la música popular masiva que surgía al mismo tiempo que el modernismo y como respuesta a los mismos fenómenos, a partir de la constatación de que, pese a los numerosos puntos de contacto, en general el modernismo literario brasileño y la música popular masiva urbana que se consolida en el curso de los años 20 no se encuentran sino $a$ posteriori, y sin embargo deben leerse en contrapunto para comprender mejor ciertos aspectos de ambos ${ }^{2}$. Me interesa aquí particularmente indagar en el modo en que en Mário la noción de síncopa articula las complejas relaciones entre el ritmo, lo nacional, lo popular y la alta cultura. Propongo, además, que sus meditaciones sobre esta noción pueden leerse como una metáfora de algunas de las contradicciones de la modernidad brasileña, de su relación conflictiva con el tiempo "homogéneo y vacío" de la modernización y de la comunidad imaginada nacional ${ }^{3}$.

La relación de Mário de Andrade con el ámbito musical es mucho más estrecha que la de otros protagonistas del modernismo brasileño, como Oswald de Andrade y Manuel Bandeira. Formado como músico de conservatorio, ejerció durante toda su vida una importante labor como docente, crítico, historiador y folclorista en este ámbito, al que están dedicados varios de sus libros publicados en vida o póstumamente. Existen numerosos estudios que abordan su labor de musicólogo y crítico musical, y los estudios dedicados a su obra literaria no han pasado por alto la importancia que las referencias musicales poseen en ella; sin embargo, en general me parece que queda

2 Este ensayo continúa el trabajo iniciado en “'Discos a todos os preços': modernismo, música y mercancía de Oswald de Andrade a Carmen Miranda”, que explora este mismo tema en la obra de Oswald de Andrade, otro de los protagonistas de la semana del 22.

La expresión “tiempo homogéneo y vacío” proviene de la décimo cuarta de las Tesis sobre el concepto de historia de Walter Benjamin, en la que se opone al tiempo-ahora, pleno, que debe ser el lugar de construcción de la historia (La dialéctica 61). La idea de la comunidad imaginada de la nación como sustentada en un tiempo homogéneo y vacío es propuesta por Benedict Anderson en su ya clásico Comunidades imaginadas (58), y lúcidamente criticada por Partha Chatterjee en La nación en tiempo heterogéneo, donde afirma que “....aunque las personas puedan imaginarse a sí mismas en un tiempo homogéneo y vacío, no viven en él. El espacio-tiempo homogéneo y vacío es el tiempo utópico del capitalismo. Linealmente conecta el pasado, el presente y el futuro, y se convierte en condición de posibilidad para las imaginaciones historicistas de la identidad, la nacionalidad, el progreso, etc., con las que Anderson y otros autores nos han familiarizado. Pero el tiempo homogéneo y vacío no existe como tal en ninguna parte del mundo real. Es utópico. (...). El tiempo es heterogéneo, disparmente denso" (62). 
todavía bastante por hacer en la tarea de conectar la estética musical y la poética de Mário, que es lo que las páginas siguientes se proponen, de manera todavía tentativa. Abordaré en ellas primero la relación de Mário con la música popular urbana masiva, el folclore y la música docta, para luego comentar pasajes de su obra en los que la síncopa aparece como un elemento articulador de esos niveles.

\section{$* * *$}

Lo primero que debe constatar quien se interese por comprender la relación del modernismo brasileño con el surgimiento de una música popular urbana de consumo masivo es que se trata de desarrollos paralelos que en un primer momento prácticamente no se tocan. Pese a que en 1917 se graba el primer samba oficialmente registrado como tal, "Pelo telefone", al mismo tiempo en que tiene lugar la exposición de Anita Malfatti que, según el propio Mário inicia la revelación que culminaría en la semana de arte moderna, y pese a que al mismo tiempo que ocurre la semana del 22, Pixinguinha y los batutas están ya exportando a París la música popular brasileña en un movimiento que dialoga de modo complejo con el descubrimiento de Brasil que Oswald realizaría en un atelier de la Place de Clichy, en general, como ha mostrado muy bien José Miguel Wisnik en diversos ensayos ${ }^{4}$, la música que le interesa explícitamente a los modernistas es música docta, artística, culta, de élite (o bien la música folclórica, “auténticamente popular”, en la que ésta debía inspirarse según Mário) $)^{5}$.

Esta distancia entre el modernismo y la cultura de masas parece a primera vista corresponder a lo que Andreas Huyssen ha llamado la "gran división"

$4 \quad$ O coro dos contrários: a música em torno da semana de 22, "Getúlio da Paixão Cearense (Villa-Lobos e o Estado Novo)”, en O nacional e o popular na cultura brasileira y “Entre o erudito e o popular”, en Brasil 1920-1950: Da antropofagia á Brasília.

$5 \quad$ Arnaldo Contier resume bien esta tensión: "Paradoxalmente, os modernistas consideravam as canções urbanas como o símbolo do 'popularesco', debido a um intenso diálogo internacional entre jazz/choro/ragtime, que negava a 'pureza' do folclore como paradigma de uma verdade histórica: 'Brasil rural'. O sucesso da tournée de Pixinguinha no cabaré Scherazade em Paris (1922), durante seis meses (momento em que passou a tocar saxofone, sob a influência do jazz); da gravação do seu chorinho 'Urubu' em Buenos Aires (fins de 1922); o afloramento de centenas de músicas gravadas; o surgimento dos artistas do rádio, durante os anos 30 , significaram para os modernistas a negação do 'nacional' e do 'popular' na música brasileira” ("Mário de Andrade e a música brasileira” 238). 
entre el modernismo y la industria cultural de comienzos de siglo ${ }^{6}$. Me parece, sin embargo, que una lectura más atenta puede señalar numerosos signos en el modernismo brasileño que apuntan en una dirección más compleja: ciertos rasgos suyos prefiguran la posterior convergencia de cultura de masas y alta cultura, por ejemplo en la relación entre el tropicalismo y la poesía concreta, o en figuras como la de Vinicius de Moraes, poeta docto y letrista de música popular, o Chico Buarque, músico popular y novelista. Esta compenetración profunda entre alta cultura, cultura popular y cultura de masas posiblemente sea un rasgo distintivo de la modernidad brasileña: Huyssen discute, por supuesto, esta relación a partir del modernismo europeo y estadounidense, y cabe preguntarse si esa división que él postula se mantiene intacta en un contexto latinoamericano. De hecho, una de las fuentes de inspiración para este trabajo fue la ausencia total de cualquier referencia al mundo latinoamericano en el interesantísimo Reading 1922, de Michael North, que justamente intenta complicar la tesis de Huyssen mostrando algunas instancias de cruces y complicidades entre el modernismo y la cultura popular contemporánea. El que su libro abordara el annus mirabilis del modernismo angloamericano, en el que se publican el Ulises, de Joyce, y La tierra baldía, de Eliot, sin tener en cuenta que en otras latitudes tenía lugar precisamente en ese año la Semana de Arte Moderna de São Paulo y la publicación de Trilce, por nombrar solo dos hechos, me pareció una indicación irresistible de que, si Raymond Williams propuso pasar del “¿qué fue el modernismo?” de Harry Levin a la pregunta “¿cuándo fue el modernismo?”, hoy en día tal vez necesitemos preguntarnos además “¿dónde fue el modernismo?”, tensionando las preguntas por la definición y la periodización con la pregunta por la mundialización 7 .

Ahora bien, retomando el modernismo brasileño, tal como en la semana de arte moderno no hubo ni cine ni fotografía, pese a que esos dos medios eran probablemente la novedad más significativa en el ámbito de la cultura visual, no hubo tampoco música popular, sino música docta, principalmente

\footnotetext{
"Sólo fortificando sus límites, preservando su pureza y su autonomía y evitando cualquier contaminación con la cultura de masas y con los sistemas significantes de la vida cotidiana, la obra de arte puede mantener su actitud negativa tanto hacia la cultura burguesa de la vida cotidiana como hacia la cultura de masas y el entretenimiento, juzgados como las formas principales de la articulación cultural burguesa" (Huyssen 106).

7 Ver Raymond Williams, “¿Cuándo fue el modernismo?” en La política del modernismo $51-56$.
} 
compuesta por Heitor Villa-Lobos ${ }^{8}$. Mário de Andrade, sin embargo, sí se interesa intensa y explícitamente en la música popular y sus relaciones con la música "erudita" desde fines de la década de los 20 (su Ensaio sobre a música popular brasileira se publica en 1928, el mismo año en que aparece su obra fundamental, la novela-rapsodia Macunaíma). Es interesante, sin embargo, que sus escritos musicales en general se centren o bien en la música que él llama "artística", o docta, o bien en la música "popular", que para él es música tradicional, anónima, folclórica, generalmente rural (aunque en esto último Mário es flexible ${ }^{10}$ ). Esta última carece, según Mário, del carácter desinteresado que permite que la música se convierta en un objeto de goce estético, pero debe constituir la base de la creación de la música propiamente artística para que esta pueda poseer carácter nacional. Este último punto, sobre el que volveremos, es fundamental para su rechazo de la música popular urbana con carácter comercial, y, sin embargo, debiera comprenderse con bastante flexibilidad, puesto que en sus ensayos de los años 40 esta concepción de la creación estética como caracterizada por su falta de finalidad social es reemplazada por la convicción opuesta, de que la obra cumple la función de criticar la vida ${ }^{11}$.

En ese sentido, parece ser que las categorías con las que Mário trabaja lo ciegan a la aparición de una nueva zona de creación musical, que no es ya folclore tradicional, aunque muchas veces lo tome como punto de partida, y que no es ya popular en el sentido de ser una creación anónima de transmisión oral, sino que se inscribe en los nuevos circuitos de producción y difusión originados por la naciente industria discográfica, y cuya relación

$8 \quad$ Para un estudio detallado de la presencia de la música popular en la semana, ver Wisnik, O coro dos contrários.

9 Sobre el uso del término "popular” en la obra de Mário y su contraste con la noción de lo "popularesco", ver el interesante artículo de Juliana Pérez González "Música folclórica”.

10 Mário afirma, en el Ensaio sobre música popular brasileira, que “...não se deberá desprezar a documentação urbana. Manifestações há, e muito características, de música popular brasileira, que são específicamente urbanas, como o Chôro e a Modinha. Será preciso apenas ao estudioso discernir no folclore urbano, o que é virtualmente autóctone, o que é tradicionalmente nacional, o que é esencialmente popular, enfim, do que é popularesco, fei a feição do popular, ou influenciado pelas modas internacionais" (167).

11 "E se a beleza é desinteressada, a arte é interessada; e é da fusão, do equilibrio entre desinteresse e interesse, que a obra de arte se torna uma crítica da vida. E aspiração a uma vida melhor” (Música doce música 355). 
con la identidad nacional es por lo mismo problemática ${ }^{12}$. Ahora bien, aunque la música que emerge en el curso de esos años no ocupe un lugar significativo en los escritos de Mário (salvo en la medida en que algunos discos comerciales sí tienen valor científico, documental, como señala él mismo antes de dar una lista de discos al final de su Ensaio sobre a música brasileir ${ }^{13}$ ), sí tenemos testimonios de que el escritor no era por completo ajeno a ella. Sin duda, el registro más interesante de la relación de Mário con la música popular masiva producida en el marco de la naciente industria discográfica son las anotaciones recopiladas por Flávia Camargo Toni en $A$ música popular brasileira na vitrola de Mário de Andrade, que recoge los comentarios del escritor en las carátulas de los discos que se iban sumando a su colección (muchos de ellos regalados por las compañías discográficas). Se trata de un apasionante rescate de la escritura de una escucha en formato suelto, que va de unas pocas frases a algunos párrafos, y que revela algo así como un lado B de la reflexión del autor sobre las relaciones entre música, cultura e identidad nacional.

Es, de hecho, precisamente la cuestión de lo nacional la que tal vez más caracteriza el abordaje que hace Mário de la música docta y popular, y el aspecto de su obra como académico y crítico musical que más influencia tuvo en la creación musical y en la musicología brasileñas. En su obra de fines de los años 20, lo nacional reaparece una y otra vez como problema y como pregunta, como objeto de esa "inquietação gostosa de procurar" (Poesias completas 121) a la que se refiere Mário en el prefacio a $O$ losango caqui, como algo que debe ser producido antes que como algo dado, como un horizonte en relación con el cual sitúa su escritura y, en algunos casos, como un criterio normativo desde el que evalúa las producciones culturales con las que se encuentra y los programas estéticos sobre los que discute. Como queda claro en sus textos críticos y en obras de carácter didáctico como su Pequena história da música (de 1942), en general Mário considera que la música docta nacionalista de Modernismo musical bateu nessa tecla: re/negar a cultura popular emergente, a dos negros da cidade, por exemplo, e todo um gestuário que projetava as contradições sociais no espaço urbano, em nome da estilização das fontes da cultura popular rural, idealizada como a detentora pura da fisionomía oculta da nação” (O nacional 133).

13 "As gravações de música popular brasileira sempre tiveram entre nós finalidade comercial. Acontece porém que algumas dessas gravações são estritamente científicas" (Ensaio 169-170). 
debe poseer carácter nacional, convicción que tuvo una importante influencia en el debate acerca de los desarrollos de la música contemporánea en Brasil ${ }^{14}$. Tal como en su obra literaria se le otorga un lugar central a la búsqueda de una lengua nacional, por ejemplo en su proyecto de "gramatiquinha da fala brasileira”, en música hay una búsqueda constante de formulación de aquellos rasgos estilísticos que podrían contribuir a producir una música propiamente brasileña. Este carácter nacional, aclara Mário en varios lugares de su obra, no puede buscarse en la armonía, un rasgo por definición internacional, sino por momentos en la melodía, y principalmente en la rítmica ${ }^{15}$.

Uno de los motivos que reaparecen constantemente en estas discusiones es el del ritmo en la música brasileña como lugar en el que se escenifica la tensión entre el mensuralismo tradicional europeo y la rítmica más libre, de carácter principalmente prosódico, propia de las músicas de raíz amerindia y africana (Ensaio 31). Este conflicto habría llevado al brasileño, "reconciliándose con los elementos extraños y acomodándose en las propias tendencias”, a producir "um geito fantasista de ritmar”, un ritmo más variado y libre que opera no solo como expresión musical sino también como "um elemento de expressão racial” (Ensaio 31) ${ }^{16}$. Me interesa detenerme por ahora solo en lo que Mário describe como el "principal problema” para la discusión del ritmo en la música brasileña, el de la síncopa. La pregunta por el modo adecuado de definir este concepto aparece una y otra vez en sus escritos sobre música,

$14 \quad$ Los textos de Flávio Silva y Sarah Tyrrell sobre la relación de Mário con Camargo Guarnieri desarrollan muy bien este aspecto de su obra.

$15 \quad$ El Ensaio sobre a música popular brasileira es tajante al respecto: “O problema da Harmonia não existe propriamente na música nacional. Simplesmente porquê os procesos da harmonização sempre ultrapassam as nacionalidades". La misma idea reaparece en $O$ banquete (133).

16 Es importante destacar aquí, aunque no profundizaremos en ella, la relación entre ritmo y raza que el Ensaio postula, y que corresponde de manera muy exacta al marco intelectual que ha descrito para el contexto europeo y norteamericano Michael Golston en su Rhythm and Race in Modernist Poetry and Science, ensayo en el que muestra cómo el pensamiento acerca del ritmo poético está conectado con nociones biológicas acerca de la raza a través de la noción de ratio o proporción, de la que se deriva el propio término "raza”. A pesar de que, como ha señalado Paulo Santos, en Mário de Andrade en muchos casos el término "raza" puede entenderse simplemente como sinónimo de cultura, y en ningún caso esté asociado a ningún tipo de determinismo biológico, parece ser que Mário no es completamente ajeno a la idea de que haya una correlación entre expresión musical, influencia del medio geográfico y etnicidad. 
preocupados con frecuencia del uso correcto de la terminología musical ${ }^{17}$, y en general Mário se inclina a comprender la síncopa popular brasileña como irreductible a la notación por medio de compases propia de la música culta europea. La cita siguiente, del Ensaio sobre a música popular brasileira, sintetiza bien algunas de sus principales reflexiones. Mário comienza notando que en la ejecución de músicas populares se mantiene la fidelidad al tempo pero no a la subdivisión del compás, y comenta:

E pela adição de tempos, talequal fizeram os gregos na maravilhosa criação rítmica deles, e não por subdivisão que nem fizeram os europeos ocidentais com o compasso, o cantador vai seguindo livremente, inventando movimentos essencialmente melodicos (alguns antiprosodicos até) sem nenhum dos elementos dinamogenicos da síncopa e só aparentemente sincopados até que num certo ponto (...) coincide de novo com o metro (...) que para ele não provêm duma teorisação mas é de essencia puramente fisiológica. Coreografica até. São movimentos livres determinados pela fadiga. São movimentos livres desenvolvidos da fadiga. São movimentos livres específicos da moleza da prosodia brasileira. São movimentos livres não acentuados. São movimentos livres acentuados por fantasia musical, virtuosidade pura, ou por precisão prosodica. Nada têm com o conceito tradicional da síncopa e com o efeito contratempado dela (Ensaio 36).

En este pasaje, que vale la pena citar in extenso por su densidad, aparecen varios motivos que obsesionaron a Mário y que posiblemente tuviera la intención de reunir en un ensayo extenso dedicado exclusivamente a este problema $^{18}$. En sus notas inéditas sobre la síncopa, agrega la idea de que la síncopa europea es especulación teórica por subdivisión, en la que los acentos mantienen sus lugares, mientras que en las músicas americanas (el jazz, el maxixe y hasta el tango) lo que se da es "um verdadeiro descolocamento do acento forte que passa do lugar teórico para um lugar onde ele não devia cair, verdadeira antecipação ritmica da thesis" (notas manuscritas sobre síncopa

17 Ver, por ejemplo, el artículo “Terminología musical”, en Música, doce música (53-56), que concluye precisamente con una discusión de las dificultades de fijar el concepto de síncopa.

18 Aprovecho aquí de agradecer a la profesora Flávia Camargo Toni, quien me confirmó la enorme importancia de la noción de síncopa en el pensamiento de Mário de Andrade y generosamente me indicó la existencia de las notas inéditas sobre el tema en el archivo del IEB. 
en el Archivo Mário de Andrade del Instituto de Estudos Brasileiros de la USP). Luego de esta insistencia en la diferencia entre la síncopa europea y la síncopa característica de la música popular en Brasil, Mário propone que esta síncopa es una realización inmediata y espontánea de nuestra manera de danzar, "provendo do clima talvez, e do amolecimento fisiologico das raças que se caldearam para nos formar e formaram também o remeleixo, o requebró, o dengue. É no movimiento dengoso do corpo na dança que deformou a rítmica da polca (...) primeiramente na rítmica da habanera (...) e em seguida no ... do maxixe.” Esta deformación de ritmos europeos no sería, según Mário, originaria de África, donde aunque se producen síncopas ello no ocurre en la melodía misma, sino que sería una creación original de América Latina, producida por el contacto entre músicas amerindias, europeas y africanas ${ }^{19}$.

Ahora bien, aquí se hacen necesarios un par de comentarios para comprender lo que está en juego. En primer lugar, está claro que para Mário la síncopa tiene una relación profunda y orgánica con la identidad racial brasileña y americana en general. Las referencias a la fatiga y la moleza (blandura) de la prosodia, que en sus notas inéditas se asocian a un ablandamiento y relajación del cuerpo debido al clima tropical que produciría los movimientos sensuales propios de la danza brasileña, no solo son aspectos comunes del discurso acerca de la raza en esa época, sino que también se asocian obviamente con las referencias a la preguiça como rasgo característico de la nación en Macunaíma (donde paradojalmente la flojera o pereza es justamente signo de la falta de carácter). La asociación entre síncopa y sensualidad reaparece en un texto tardío como O banquete, donde la cantora Siomara Ponga denuncia la síncopa como inmoral (“A síncopa é anti-moral, apaixonante, um desvio.” 134), y donde el compositor Janjão la califica como "o maior perigo da música brasileira erudita" $(136)^{20}$. de los autores, que la música negroafricana sea bastante sincopada en sus acompañamientos de percusión y sus tam-tam, pero la síncopa es rarísima dentro de la estructura melódica negro-africana, no llega a caracterizarla y ni siquiera llega a ser una constante. Uno de los elementos que distinguen esencialmente la música afroamericana, y quizá especialmente a la afrobrasileña, de la música negroafricana, es que entre nosotros la síncopa pasó a organizar el cuerpo de la misma melodía, no contentándose con formar parte del acompañamiento" (Obras escogidas 264).

20 Sobre el tratamiento de la síncopa, ver el ensayo de Marcos Napolitano "O NacionalPopular em 'O Banquete' de Mário de Andrade”. En ese ensayo, en general muy acertado, se exacerba, sin embargo, el carácter negativo de la síncopa. Creo que para matizar esa mirada 
Es interesante, por otra parte, la distinción en la que insiste Mário entre una síncopa europea, que se encontraría con frecuencia en Bach, y que sería plenamente compatible con una música culta, escrita, notada en compases, y que consistiría solo en una alteración del ritmo al interior de un sistema que produce tensión pero no modifica fundamentalmente la regularidad rítmica de la pieza, y la síncopa afroamericana, que en última instancia supondría otro modo de concebir el ritmo, ya no reductible a la regularidad homogénea de la división en compases iguales.

Me parece que la intuición que Mário registra en estas líneas, y que retorna una y otra vez en sus escritos musicales, no es solo de carácter técnico, pese a que su punto de partida es efectivamente un problema técnico musical referido a cómo se debe conceptualizar la síncopa y a cómo su definición tradicional ("el desplazamiento del acento musical de un tiempo fuerte a un tiempo débil”, en el Oxford Companion to Music, citado en Temperley 20) entra en crisis al encontrarse con músicas populares en las que esa definición o bien parece equivocada, o bien no da cuenta de cómo la síncopa efectivamente funciona ${ }^{21}$. Este problema ha aparecido también en discusiones recientes sobre la música popular brasileña, como la de Carlos Sandroni acerca de la rítmica del samba, en la que propone incluso renunciar a la noción de síncopa y reemplazarla por la de contrametricidad, o metricidad compleja (Feitiço decente 19-37). En Mário, sin embargo, este aspecto técnico es también una clave de entrada a las relaciones entre lo nacional, la modernidad, lo popular y la estética, una clave que puede servirnos además para pensar la temporalidad del modernismo brasileño, tensionado entre las atracciones de lo primitivo y lo contemporáneo, de lo regional y lo cosmopolita, de la máquina y de lo ritual, lo popular y lo erudito. Si esa tensión se ha conceptualizado

sobre la síncopa sería preciso recordar, como señala el propio Napolitano, que O banquete es un texto dialógico, en el que no todas las voces representan la opinión del propio Mário, y habría que tener presente también la distinción que hace insistentemente el propio Mário entre una síncopa esquemática, resultado de la transcripción torpe de la rítmica brasileña a un sistema de escritura con compases fijos, y la síncopa "auténtica" descrita en el párrafo citado más arriba y explicada en detalle en las líneas siguientes. Aprovecho aquí de reconocer al profesor Napolitano su amable ayuda en la ubicación de muchas de las referencias que fueron utilizadas para la elaboración de este ensayo.

$21 \quad$ Una discusión interesante es el texto de David Temperley "Syncopation in Rock: A Perceptual Perspective”, que muestra las complicaciones de la concepción clásica de síncopa en la música rock y propone un modelo cognitivo para comprender el modo en que se la percibe en la escucha. 
en términos de "modernidad híbrida" (García Canclini), "modernidad periférica” (Sarlo) y "modernidad primitiva” (Garramuño), yo propondría agregar la noción de "modernidad sincopada”, en diálogo con lo que Ernst Bloch llama Ungleichzeitigkeit, una expresión que puede traducirse por "no sincronicidad": el conjunto de tiempos en conflictos que subyacen a un presente no homogéneo, que se debe comprender a partir de una dialéctica multiespacial y multitemporal, cargada de contrapuntos y polirritmias, una dialéctica polifónica de la contradicción ("Nonsynchronism" 37-38). Esta dialéctica permite articular de modo muy preciso algunas de las preguntas más potentes que plantea el modernismo brasileño, y permite comprender mejor sus relaciones con el contexto global y mundial de la modernidad. La síncopa funciona entonces no solo como una metáfora de lo brasileño (como propone Mário) sino como una metáfora de las contradicciones del proyecto modernista de Mário y del modernismo en general, encarnadas en esta figura que se puede describir como un acento desplazado, como la coexistencia dialéctica de diversas temporalidades contradictorias, o como una evasión de las restricciones del metro, del tiempo homogéneo y vacío, hacia un tiempo que dialoga más directamente con el movimiento de los cuerpos y los ritmos de un lenguaje en sintonía con ellos.

Puede parecer abusivo convertir una figura o recurso rítmico musical en una figura conceptual de esta manera; sin embargo, creo que al hacerlo estoy siguiendo las señas que da el propio Mário cuando, por ejemplo, en el texto “Dinamogenias políticas” (Música, doce música 96-103) propone escuchar los ritmos con los que se gritan slogans políticos en una concentración de homenaje a Getúlio Vargas (y que Mário transcribe cuidadosamente) como "manifestaciones líricas del alma colectiva”, en las que la mutación de acento de una célula rítmica es "claramente reaccionaria y altiva. (...) Reacciona contra [la fatalidad] y, utilizando los mismos valores de tiempo, disloca la 'tesis' y, en vez de aceptarla finalmente, como un golpe, la transporta para el principio, como si fuese un ímpetu, un nombrar, un impulso" (Música doce música 102). Me parece que esta escucha de la síncopa como síntoma político es una importante pista para comprender las implicancias más radicales del pensamiento de Mário en torno a la música y sus posibilidades metafóricas.

Por otra parte, creo que es esa misma tensión entre múltiples dinámicas temporales en conflicto la que mejor caracteriza la relación de Mário y del modernismo con la música popular, en sus vertientes folclóricas. La misma tecnología que permite registrar el folclore tradicional auténtico en su supuestamente prístina pureza, antes de que sea contaminado por 
la modernidad, es la que lo modifica al exponer a los músicos rurales y regionales a emisiones radiales y grabaciones fonográficas de músicas recientes $^{22}$. La misma tecnología que permite constituir un archivo sonoro nacional, un "museo de discos" que conserve la brasilidad de la música brasileña tradicional antes de que sea olvidada (un proyecto muy querido para Mário), es la que convierte a la música en mercancía, en objeto de consumo sometido a los vaivenes del gusto del público, en lo que Mário llamaría más adelante "sub-música, carne para alimento de radios y discos, elemento de galanteo e interés comercial, con que fábricas, empresas y cantantes se sustentan" (citado en Pérez González 2). La relación etnográfica de Mário con la música popular tradicional, folclórica, que sirve de base en muchos casos tanto para la música popular urbana comercial y masiva (que la degrada y contamina) y para la música docta (que la eleva a una esfera estética en la que trasciende su carácter utilitario y circunstancial) parece ser un caso de lo que James Clifford ha llamado "alegoría etnográfica", la percepción de un otro primitivo, intocado por la modernidad, que se encuentra a punto de desaparecer y que la escritura puede rescatar del olvido, aunque al mismo tiempo forma parte del proceso de contacto que producirá su contaminación (Writing Culture 98-121).

Por otra parte, es preciso indicar también que la síncopa es abordada en Mário con una marcada ambivalencia respecto a su carácter moral, al ethos del que es un síntoma, como puede verse en sus crónicas, críticas y ensayos sobre música, así como en su obra narrativa. Quedará para un próximo trabajo un desarrollo más detallado de la presencia de la síncopa en estos ámbitos, por ahora me interesa demorarme en revisar las referencias a la síncopa que aparecen en la poesía de Mário, específicamente en sus tres primeros libros de poemas (excluyendo el inmaduro Há uma gota de sangue), a la luz de los problemas recién articulados ${ }^{23}$.

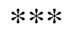

22 Sobre este tema, ver "E Se você jurar, 'Pelo telefone', que estou na Missão de Pesquisas Folclóricas?”, de José Geraldo Vinci de Moraes.

23 Ver, sobre este tema, Clã do jabuti: uma partitura de palavras, de Cristiane Rodrigues de Souza, que explora el tema de la música en estos mismos libros y que contiene observaciones interesantes respecto a la presencia de la síncopa en ellos. 
En general, Paulicéia desvairada (escrita en 1920) discute y practica el ritmo en relación con el problema del verso libre, y el proyecto de estructurar musicalmente su libro en base al montaje de imágenes que se suceden y superponen con una rítmica que es la de la metrópolis paulista de inicios de siglo, según "el orden imprevisto de las conmociones, de las asociaciones de imágenes, de los contactos exteriores" (19). Sucede así, por ejemplo, en el poema "La cacería”, en cuya cuarta estrofa se lee:

A velhice a a riqueza têm as mesmas cãs.

A engrenagem trepida... A bruma neva...

Uma síncope: a sereia da policía

que vai prender um bêbado no Piques... (Poesias completas 94) ${ }^{24}$

El poema, que concluye con una célebre imagen de Oswald de Andrade "mariscando genios entre la multitud”, es un ejemplo bastante típico del estilo de Paulicéia, con su alternancia entre puntos suspensivos y signos de exclamación, su acumulación paratáctica de percepciones que inundan la conciencia del poeta, que no parece ser capaz de articularlas en un total coherente sino que las recoge como "un montón de imágenes quebradas", para utilizar el famoso verso de Eliot en La tierra baldía. La síncopa parece ser, en este caso, una manifestación más del caos urbano, de la metrópolis infernal que es causa de la conmoción del poeta, de su "desvairismo". Al mismo tiempo, no deja de ser curioso que la síncopa sea aquí el sonido de una sirena de policía, un ejemplo de las fuerzas del orden castigando toda transgresión de la convivencia civilizada, evitando cualquier disturbio que amenace el orden de la bien engrasada máquina urbana. Es posible también que no sea casual que en este caso la policía vaya camino a aprehender a un borracho, y que esta presencia de la policía ocurra también en el primer samba grabado, "Pelo telefone” ("O chefe da policía pelo telefone mandame avisar...”).

El siguiente libro de Mário, escrito en 1922 durante su servicio militar y publicado en 1926, mantiene y desarrolla el verso libre del volumen anterior, aunque podría decirse que el grado de fragmentación de la conciencia que en él se percibe es menor, tal vez por el entorno rural que se perfila en los

24 "La vejez y la riqueza tienen las mismas canas. / El engranaje trepida... La bruma nieva / Una síncopa: la sirena de la policía / que va a apresar a un borracho en el Piques... (Paulicea desvariada 59). 
poemas, en los que el ritmo entrecortado de las percepciones y pensamientos que registra Mário contrasta por momentos con el ritmo regular de la marcha de los ejercicios militares: "Soldado-raso da República. / Quarto batalhão de Caçadores aquartelado em Sant'Anna. / Rogai por nós! / Valha-me Deus! / Todo vibro de ignorâncias militares./...O calcanhar direito se levanta, / Corpo inclinado pra frente..., / A marcha rompe. / Marcha, soldado, Cabeça de papel, / Soldado relaxado / Vai preso pro quartel...” (Poesias completas 126-127). Nuevamente vemos en estos versos una tensión fuerte entre el ritmo regular, de marcha, de la colectividad, y la tendencia a dejarse llevar por el ritmo mole de la síncopa, por el relajo (que es cortada en seco por la amenaza de prisión $)^{25}$. No es casualidad también que esta marcha regular se asocie a la "República", al Estado-nación en sus manifestaciones más vehementes y forzadas, en tanto que instancia que regulariza, regula, vigila y castiga a quienes se apartan del tiempo homogéneo y vacío que impone. Es, sin embargo, en otro poema que vale la pena citar completo, titulado "Cabo Machado”, donde aparece resaltada explícitamente la figura de la síncopa:

Cabo Machado é cor de jambo,

Pequenino que nem todo brasileiro que se preza.

Cabo Machado é um moço bem bonito.

É como si a madrugada andasse na minha frente.

Entreabre a boca encarnada num sorriso perpétuo

Adonde alumia o Sol de ouro dos dentes

Obturados com luxo oriental.

Cabo Machado marchando

É muito pouco marcial.

Cabo Machado é dançarino, sincopado,

Marcha vem-cá-mulata.

Cabo Machado traz a cabeça levantada

Olhar dengoso pros lados.

Segue todo rico de jóias olhares quebrados

Que se enrabicharam pelo posto dele

E pela cor-de-jambo.

25 Como señala Cristiane Rodrigues de Souza, “Ao ingresar no exército (...) o poeta, após clamar pela proteção divina em expressão típica da religiosidade brasileira (...) inicia sua marcha no ritmo da quadrinha popular, mostrando em tom de blague, a inadequacão do ritmo brasileiro às convenções militares" (49). 
Cabo Machado é delicado, gentil.

Educação francesa mesureira.

Cabo Machado é doce que nem mel

E polido que nem manga-rosa.

Cabo Machado é bem o representante de uma terra

Cuja Constituição proíbe as guerras de conquista

E recomenda cuidadosamente o arbitramento.

Só não bulam com ele!

Mais amor menos confiança!

Cabo Machado toma um jeito de rasteira...

Mas traz unhas bem tratadas

Mãos transparentes frias,

Não rejeita o bom-tom do pó-de-arroz.

Si vê bem que prefere o arbitramento.

E tudo acaba em dança!

Por isso cabo Machado anda maxixe.

Cabo Machado...bandeira nacional! (Poesias completas 144)

Se trata de un texto fuertemente cargado de ambigüedad en varios niveles. El retrato del cabo Machado tiene una dosis no menor de comicidad, y casi de ironía cruel, no carente de cierto homoerotismo. El retrato comienza aludiendo a su color moreno ${ }^{26}$, para luego destacar su pequeñez y su belleza, concentrada en particular en su sonrisa luminosa (que no por casualidad se vincula a un oriente que tiene mucho de los estereotipos denigratorios respecto a la otredad que el famoso trabajo de Edward Said sacó a relucir).

Es posiblemente el mismo lujo oriental de esa sonrisa el que hace que el Cabo no tenga, sin embargo, al marchar, un aire suficientemente marcial (palabra que rima con “oriental”, acentuando el contraste entre ambos términos). Por otra parte, al enunciar esa característica, los dos primeros versos de la segunda estrofa parecen anunciar un ritmo regular que los versos siguientes no mantienen ${ }^{27}$. Se detalla en esa estrofa su manera bailarina, sincopada, irregular de marchar, que tiene mucho de femenino (por ejemplo, la mirada melindrosa, coqueta, que lanza hacia los lados al avanzar), y la

26 El jambo tiene la peculiaridad de ser tanto un pie métrico (de dos sílabas, una breve y una corta) como una fruta de cáscara rojiza.

$27 \quad$ Se trata de dos versos de redondilha maior, de siete sílabas en portugués equivalentes al octosílabo español. 
estrofa siguiente prolonga esas connotaciones aludiendo a su delicadeza, su ceremoniosa (o servil) educación francesa, su dulzura y suavidad. Su marcha "vem-cá-mulata” probablemente alude a una música grabada originalmente en 1906 con ese título, y con la etiqueta de "Tango-chula ou polca-chula", aunque su ritmo suele catalogarse como de maxixe. Se trata de una música de carnaval, que claramente remite a un ethos sensual, gozador, bohemio, diametralmente opuesto al ánimo viril que supuestamente debiera imperar entre los soldados ${ }^{28}$.

Sin embargo, en el verso 21 del poema ocurre un giro: el Cabo Machado no es ya solamente una figura cómica de masculinidad dudosa (muy en línea con ciertos estereotipos raciales respecto a los mulatos), sino que se convierte en "representante de una tierra / Cuya constitución prohíbe las guerras de conquista", en una figura de la brasilidad, caracterizada aquí por la resolución de conflictos por medio del arbitraje, o la danza: "Por eso el cabo Machado anda maxixe" (144). No hay certeza de que las connotaciones de este retrato sean enteramente positivas (de hecho, el cabo Machado podría verse como una prefiguración de algunos rasgos de Macunaíma), pero sí está relativamente claro que se trata de una figura con la que Mário en parte se identifica, y que al mismo tiempo está cargada libidinalmente de manera muy ambigua. En un libro atravesado por la tensión entre el ritmo de marcha (ver el poema XIV) y la tendencia brasileña a la pereza, la sensualidad, el desacato, el cabo es un ejemplo de una resolución no binaria de conflictos, de un ambiguo tercer tiempo que se inserta entre los dos, precisamente a la manera en que la síncopa desplaza los acentos regulares de un compás hacia los tiempos débiles, femeninos ${ }^{29}$. Si el “tupi tangendo um alaúde” de Paulicéia desvairada ha sido leído como una figura que reconcilia el cosmopolitismo sofisticado con el primitivismo, el Cabo Machado debiera leerse como una figura que reconcilia el tiempo homogéneo y vacío del Estado-nación con el tiempo sincopado de los cuerpos singulares brasileños ${ }^{30}$.

Aquí puede oírse la grabación de esa música, de autoría de Arquimedes de Oliveira, con letra de Bastos Tigre, e interpretada por Duarte Silva e Isabel Costa: http://www.youtube. com/watch?v=eOgyAy4W8T0.

Otro ejemplo de esta tensión es la referencia al cabo que camina en contratiempo en el poema "Parada".

30 La figura del "Cabo Machado" resuena de manera notable, aunque sea por la coincidencia de nombres, con la descripción de Machado de Assis y su personaje Pestana que 
En el tercer libro de poemas de Mário, Clã do jabuti, la síncopa no solo hace una aparición fugaz en el poema que inaugura el volumen, "Carnaval carioca", sino que sirve de título a su penúltima sección, "O ritmo sincopado”, que reúne poemas escritos entre 1923 y 26 (el libro se publica en 1927). Florencia Garramuño ha descrito acertadamente el modo en que en este se produce "un vaivén entre la descripción de una fiesta colectiva y el impacto que sobre un sujeto esa experiencia produce; una oscilación constante entre descripción externa, objetiva e, incluso, mimética, y enunciación confesional o relato de la experiencia subjetiva del yo lírico en el carnaval" (125), un texto en el que las fronteras entre uno y otro tipo de enunciación son difíciles de localizar, y en el que Mário alterna entre lo que él describe como su "frialdad de paulista / policiamientos interiores / temores de la excepción” y una fascinación con el carácter orgiástico de la fiesta popular, entre la distancia apolínea y el éxtasis dionisíaco, asociado aquí a lo negro y primitivo. No es casualidad que, vinculada a su identidad de paulista, pero también a su intelectualismo, a su relación con la cultura erudita y literaria, aparezca la noción de una policía interior (claramente ligada a instancias represoras como la de la policía en el poema de Paulicéia o a los oficiales en O losango caqui).

Este conjunto de tensiones puede verse claramente en la primera sección del poema, en la que luego de un extenso preludio, Mário escribe:

Em baixo do Hotel Avenida em 1923

Na mais pujante civilização do Brasil

Os negros sambando em cadência.

Tão sublime, tão áfrica!

A mais moça bulcão polido ondulações lentas lentamente

Com as arrecadas chispando raios glaucos ouro na luz peluda de pó.

Só as ancas ventres dissolvendo-se em vaivéns de ondas em cio.

Termina se benzendo religiosa talqualmente num ritual.

E o bombo gargalhante de tostões

Sincopa a graça da danada. (Poesias completas 167)

Sabemos por una carta a Carlos Drummond de Andrade que esta experiencia (y esta escena en particular) tuvo para Mário un carácter epifánico. Como 
explican las notas de las Poesias completas, el 10 de noviembre de 1924 Mário le escribe a Drummond y le cuenta

...um fato a que asisti em plena avenida Rio Branco. Uns negros dançando o samba. Mas havia uma negra moça que dançava melhor do que os outros. Os jeitos eram os mesmos, mesma habilidade, mesma sensualidade mas ela era melhor. Só porque os outros faziam aquilo um pouco decorado, maquinizado, olhando o povo em volta deles, um automóvil que passava. Ela, não. Dançava com religião. Não olhava pra lado nenhum. Vivia a dança. E era sublime. Este é um caso em que tenho pensado muitas vezes. Aquela negra me ensinou o que milhões, milhões é exagero, muitos libros não me ensinaram. Ela me ensinou a felicidade. (Poesias completas 508)

Se trata, por cierto, de una escena reconocible: un espectador masculino extasiado ante una danzarina femenina entregada por completo al movimiento y a su mirada, hasta el punto de carecer por completo de conciencia de estar siendo observada (es lo que la distingue de sus compañeros, en los que Mário siente algo de artificial y mecánico). Sin embargo, me parece que en el poema la identificación predomina por sobre el voyerismo que aparece en la carta: Mário se siente arrastrado por el torbellino oscuro de la danzarina, se siente participante en un ritual de carácter religioso en el que, por el ritmo, los cuerpos se coordinan y comunican. El poema continúa con su oscilación entre esa fascinación identificatoria, el goce de que se difuminen las fronteras del yo, y la resistencia a esa experiencia, entre la alabanza exaltada al creador y las observaciones del poeta que no deja de lado su conciencia crítica, hasta que llega la conclusión en la que el poeta "duerme sin necesidad de soñar", arrullado por el estrépito urbano de las campanas, campanillas y bocinas de la mañana en Guanabara. La síncopa llena de gracia de esta figura femenina no es, claramente, la síncopa mecánica que Mário condena en otras ocasiones (y que tal vez es la que ponen en práctica sus comparsas, demasiado conscientes de la presencia de sus espectadores), y en este caso la sensualidad de la escena parece romper las barreras de su "policía interior": se trata de una imagen de brasilidad pura, de placer sin culpa, de felicidad, opuesta a la cultura libresca y a la inteligencia crítica, que sin embargo Mário no dejaría de cultivar hasta el final de sus días.

En el caso de la sección "O ritmo sincopado" del mismo libro, no encontramos nada parecido a ese entusiasmo orgiástico. Se alternan en ella poemas de tono más bien descriptivo, como “Arraiada”, “Tempo das águas” y 
"Paisagem n ${ }^{\circ} 5$ " con textos de factura pseudo-popular, vinculados obviamente a los intereses etnográficos del poeta que luego darían origen a Macunaíma (de hecho, la "Toada do Pai-do-Mato" se atribuye a los indios parecís). Se trata de textos de carácter narrativo, anecdótico, con estructuras estróficas recurrentes típicas de las composiciones orales (se los identifica como "coco", "toada", "lenda” y “moda”) y folclóricas, y por lo mismo se vinculan también al interés de Mário en producir un portugués literario brasileño. Curiosamente, en términos de métrica utilizan tipos de versos relativamente regulares, con algunas interrupciones. En esta sección, parecería que el ritmo sincopado tiene que ver con la identificación del poeta con la colectividad, con un esfuerzo por salir de sus propias conmociones de conciencia y volverse una voz de la colectividad nacional, como había anunciado que pretendía hacer en la “Advertencia” que precede a los poemas de $O$ losango cáqui, en que se disculpa por el foco excesivo en su existencia personal, que siente que es un deber de la poesía superar. Lo sincopado es, entonces, aquí, lo regional y popular elevado a la categoría de lo nacional-universal. Contra el subjetivismo por momentos exacerbado que caracteriza a muchos de los poemas de Paulicéia desvairada y O losango cáqui, y a varios de los poemas más extensos de Clã do jabuti, en los textos de la sección "El ritmo sincopado" se percibe una poética en la que el sujeto está como elidido, en algunos casos a favor de la descripción (“Arraiada”, “Tempo das águas”, “Paisagem n5”) y en otros a favor de la narración tradicional, anónima, de origen oral. Se podría pensar que se trata del esfuerzo de Mário por superar los límites de su personalidad, y de la poesía romántica hecha a partir de las sensaciones subjetivas de un sujeto individual. El fruto más importante de este esfuerzo sería, por supuesto, su obra Macunaíma, pero puede decirse que toda la etapa tardía de su obra está bajo el signo de este esfuerzo por superar el individualismo romántico que habría caracterizado su obra temprana ${ }^{31}$.

El libro Clã do jabuti concluye con los "Dos poemas acreanos", que pueden leerse en este contexto como un intento de reconciliar los impulsos individualistas con la idea de nación y de comunidad. El primer poema contrasta una imagen del autor en su escritorio de São Paulo con la imagen de un seringueiro, un recolector de caucho, en el estado de Acre, al noroeste del país, y concluye afirmando "Esse homem é brasileiro que nem eu" (Poesias completas 203), ese hombre es tan brasileño como yo. La imagen claramente 
es un intento de superponer un Brasil rural, primitivo, y pobre, con el Brasil burgués, letrado y urbano del que forma parte el poeta, y un intento de superar esa oposición en algún tipo de síntesis, por medio de la idea de nación. El segundo texto es una canción de cuna para hacer dormir al seringueiro, que concluye con el verso repetido de manera hipnótica: "Brasileiro...dorme..." (206). Tal como en el dormir sin sueños de "O carnaval carioca", en este caso se puede pensar que el adormecerse elimina las contradicciones entre un Brasil urbano, moderno, y un Brasil rural, arcaico.

$* * *$

Esta breve revisión muestra algunos de los modos en que la síncopa aparece en la obra ensayística y poética de Mário como una clave para pensar las relaciones equívocas de Brasil con la modernidad. Las problemáticas relaciones de América Latina con la modernidad se han pensado en términos de lo periférico (Sarlo), lo primitivo (Garramuño), lo híbrido (García Canclini) y el desencuentro (Ramos), entre otros. Me parece que a estas caracterizaciones se podría agregar la de lo sincopado, como metáfora de la emergencia, en regiones periféricas, de un tiempo heterogéneo que se resiste tanto al cosmopolitismo como al nacionalismo, en tanto que proyectos homogeneizadores, y al mismo tiempo, paradojalmente, en el caso brasileño y en la obra de Mário opera como un punto de partida para un proyecto que se propone reconciliar lo moderno con lo nacional. Aunque no concordemos hoy en día con la problemática ideología que implica asumir una relación fundante entre ritmo, cuerpo, raza, nación, cultura popular y alta cultura, como lo hace con frecuencia Mário, no podemos sino reconocer la perspicacia con la que el autor se plantea algunos de los problemas centrales de la modernidad brasileña, consciente de sus paradojas, pero también de su potencial crítico. Una de las ventajas de abordar la obra de Mário desde este ángulo es precisamente su inestabilidad, y la dificultad del autor para utilizarlo como punto de partida de un programa coherente. Como señala el propio Mário en una crónica sobre el sambista Sinhô, “este nosso país inda pode dar esperança de si... Mas simplesmente porque arromba toda concepção que a gente se faça dele" (citado en A música popular 80). Lo sincopado en Mário de Andrade sería precisamente esa imposibilidad de reconciliación consigo mismo, esa insistente diferencia que, como hemos mostrado en las páginas precedentes, opera como una metáfora del conjunto de tensiones dialécticas que para Mário constituyen la heterogeneidad irreductible de lo nacional en sus tensiones con el cosmopolitismo, la modernidad, la cultura y la música. 


\section{BIBLIOGRAFÍA}

Anderson, Benedict. Comunidades imaginadas. México, DF: Fondo de Cultura Económica, 1993.

Andrade, Mário de. Música, doce música. São Paulo: Martins, 1976.

Obra escogida. Ed. Gilda de Mello e Souza. Caracas, Venezuela: Ayacucho, 1979. Poesias completas. Ed. Diléa Zanotto Manfio. Belo Horizonte: Itatiaia, 1987. O banquete. São Paulo: Duas ciudades, 1989. Paulicea desvariada. Buenos Aires: Beatriz Viterbo, 2012.

Benjamin, Walter. La dialéctica en suspenso. Fragmentos sobre la historia. Trad. Pablo Oyarzún. Santiago: Arcis-Lom, 1996.

Bloch, Ernst. “Nonsynchronism and the Obligation to Its Dialectics” Trad. Mark Ritter. New German Critique 11 (Primavera 1977): 22-38.

Chatterjee, Partha. La nación en tiempo heterogéneo. Buenos Aires: Siglo XXI, 2008.

Clifford, James y George E. Marcus (eds.). Writing Culture: the Poetics and Politics of Ethnography. Berkeley y Los Angeles, CA: California University Press, 1986.

Contier, Arnaldo Daraya. “Mário de Andrade e a música brasileira” En Múltiplo Mário: ensaios. Maria Ignez Novais y Ayala Eduardo de Assis Duarte organizadores. Pernambuco: UFBP editora universitaria, 1997.

De Souza, Cristiane Rodrigues. Clã do jabuti: uma partitura de palavras. São Paulo: Annablume, 2006.

Garramuño, Florencia. Modernidades primitivas. Tango, samba y nación. Buenos Aires: Fondo de Cultura Económica, 2007.

Golston, Michael. Rhythm and Race in Modernist Poetry and Science. Nueva York: Columbia UP, 2008.

Huyssen, Andreas. Después de la gran división : modernismo, cultura de masas, posmodernismo. Buenos Aires: Adriana Hidalgo, 2002.

Napolitano, Marco. “Allegro ma non danzante: O Nacional Popular em 'O Banquete' de Mário de Andrade”, Latin American Music Review / Revista de Música Latinoamericana, Vol. 24, No. 1 (primavera verano 2003): 126-135.

North, Michael. Reading 1922. A Return to the Scene of the Modern. Oxford: Oxford UP, 1999.

Pérez González, Juliana. "Música folclórica, popular y popularesca: Tres conceptos en la obra de Mário de Andrade (1893-1945) sobre la vida musical", http://www.memoriadamusica. com.br/site/images/stories/a\%20-\%20texto\%20juliana\%20mda.pdf Consultado el 27/09/13.

Sandroni, Carlos. Feitiço decente. Transformações do samba no Rio de Janeiro (1917-1933). Rio de Janeiro: Jorge Zahar, 2001.

Mário contra Macunaíma. Cultura e política em Mário de Andrade. São Paulo: Vertice, 1988.

Santos, Paulo Sérgio Malheiros dos. Músico, doce músico. Belo Horizonte: editora UMFG, 2004. 
Silva, Flávio. “Camargo Guarnieri e Mário de Andrade”, Latin American Music Review / Revista de Música Latinoamericana, Vol. 20, No. 2 (Otoño-invierno 1999): 184-212.

Temperley, David. “Syncopation in Rock: A Perceptual Perspective .” Popular Music, Vol. 18, No. 1 (Enero 1999): 19-40.

Toni, Flávia Camargo. A música popular brasileira na vitrola de Mário de Andrade. São Paulo: Senac, 2003.

Tyrrell, Sarah. "M. Camargo Guarnieri and the Influence of Mário de Andrade's Modernism” Latin American Music Review / Revista de Música Latinoamericana, Vol. 29, No. 1 (Primavera-verano 2008): 43-63.

Vinci de Moraes, José Geraldo."E Se você jurar, Pelo telefone, que estou na Missão de Pesquisas Folclóricas?” Revista USP 87, nov. 2010: 172-183. http://www.revistas.usp. br/revusp/article/view/13839/15657. Consultado el 27/09/13.

Williams, Raymond. La política del modernismo. Contra los nuevos reformistas. Buenos Aires: Manantial, 2002.

Wisnik, O Córo dos Contrários: a música em torno da semana de 22. São Paulo: Livraria Duas Cidades, 1977.

“Getúlio da Paixão Cearense (Villa-Lobos e o Estado Novo)”, O nacional e o popular na cultura brasileira. São Paulo: Brasiliense, 1982.

“Entre o erudito e o popular”, Revista de História 157, Universidade de São Paulo. 2007:55-72. http://www.redalyc.org/pdf/2850/285022050004.pdf. Consultado el 27/09/13. Sem receita. Ensaios e canções. São Paulo: Publifolha, 2004. 